\title{
A CULTURA DA CANA-DE-AÇÚCAR COMO CONTEXTUALIZAÇÃO PARA O PROCESSO DE ENSINO E APRENDIZAGEM NA ÁREA DE CIÊNCIAS DA NATUREZA
}

\author{
Juliane Cristina Fabre Borges $^{1^{*}}$ Ana Maria de Andrade Caldeira ${ }^{2 *}$ \\ Universidade Estadual Paulista
}

\section{RESUMO}

O presente estudo procurou investigar as questões relativas à contextualização para o processo de ensino e aprendizagem na área de ciências da natureza através de um trabalho interdisciplinar dos professores dessa área, tendo como elemento norteador o tema Energia e suas relações com o ambiente e a sociedade. A temática desenvolvida foi o cultivo da cana-de-açúcar devido a sua grande influência na região onde a unidade escolar, que abrigou o projeto, está inserida. O estudo apresentou três etapas distintas: a primeira foi à elaboração do projeto pelos professores da unidade escolar; a segunda foi à aplicação do projeto nas $3^{a}$ séries do Ensino Médio (período noturno); e a terceira foi à análise dos resultados obtidos.

Palavras-chave: ensino de ciências, contextualização, interdisciplinaridade, CTS, energia

\begin{abstract}
The present study it looked for to investigate the relative questions to the context for the education process and learning in the area of sciences of the nature through a work to interdisciplinary of the professors of this area, having as element conductor the subject Energy and its relations with the environment and the society. The thematic one developed was the culture of the cane-of-sugar due its great influence in the region where the pertaining to school unit that sheltered the project is inserted. The study it presented three distinct stages: the first one was to the elaboration of the project for the professors of the pertaining to school unit; second it was to the application of the project in $3^{\text {a }}$ series of High School (nocturnal period); e third was to the analysis of the gotten results.
\end{abstract}

Key-words: education of sciences, context, interdisciplinary, CTS, energy

\footnotetext{
${ }^{1}$ UNESP - Doutoranda em Educação para a Ciência; julianefabre@ yahoo.com.br

${ }^{2}$ UNESP - Professora Adjunta do Departamento de Educação da Universidade Estadual Paulista - Bauru

* Membro do Grupo de Pesquisa em Educação Científica do programa de Pós-Graduação em Educação para a Ciência - UNESP Bauru
} 


\section{INTRODUÇÃO}

Observamos uma crescente preocupação entre os educadores quanto à incorporação, nas atividades de ensino, de aspectos abrangendo a relação do ser humano com o ambiente, com o objetivo de abordar a depredação provocada pelo homem sobre os componentes da biosfera, a destruição da biodiversidade e a necessidade de incorporação de valores e objetivos relativos aos aspectos sociais, econômicos e políticos no processo de produção do conhecimento científico e tecnológico.

A escola deve subsidiar o desenvolvimento de conhecimentos, idéias, atitudes e pautas de comportamento que permitam ao aluno uma incorporação eficaz, no mundo civil, no âmbito da liberdade de consumo, de escolha, participação política e responsabilidade na esfera da vida familiar. (GIMENO SACRISTÁN \& PÉREZ GÓMEZ, 1998).

Os Parâmetros Curriculares Nacionais (BRASIL, 1999) quanto às Ciências Naturais, proporcionam meios para que o aluno, através do ensino, desenvolva competências que lhe permitam compreender o mundo em que vive e atuar como indivíduo e cidadão, utilizando-se de conhecimentos de natureza científica e tecnológica. Destacam ainda uma sociedade que convive com a supervalorização do conhecimento científico e a crescente intervenção da tecnologia no cotidiano, não é possível pensar a formação de um cidadão crítico à margem do saber científico.

Um princípio que caracteriza essa compreensão é a complexidade que se anuncia pela busca de conceitos que possam articular-se com as diversas áreas do saber; devemos, também, unificar os termos e códigos, incentivar a investigação interdisciplinar, o estabelecimento de vínculos entre a natureza e a cultura, relacionar a problemática cientifica com a ideológica para uma tomada de consciência global e a utilização de diferentes metodologias. Devemos proporcionar a construção de significados, os modelos não devem centrar-se somente no professor ou apenas no aluno, mas devem ocorrer sempre em comunicação e interação entre esses. Uma concepção da aula como sistema complexo e singular, deve reconhecer a diversidade existente nos indivíduos, nos grupos, nas situações de classe e de contexto. (GARCIA, 1988).

Segundo Morin (1996) as descobertas científicas moldam a sociedade e intervêm nela diretamente. A ciência é um processo e não um produto. Devemos enfatizar a 
percepção de alunos e professores para esse processo de construção da ciência, impregnado de valores sociais, políticos, históricos, econômicos e culturais.

O desenvolvimento das aulas deve observar a riqueza da sala de aula quanto à sua estrutura e às suas relações internas e externas, elucidar os processos comunicativos interindividuais e grupais tentando diminuir a incidência de fatores que possam produzir obstáculos ao fluxo da informação, selecionar informações potencialmente significativas estimulando a motivação intrínseca e entender a diversidade como variedade de manifestações dentro de uma ordem, referidas a uma organização e não como, muitas vezes confundidas, com a idéia de caos ou desordem. (CAÑAL, 1988).

A comunicação em aula apresenta um grande fluxo de informações que provem de diversas fontes de emissão, distintos canais, códigos e mecanismos de regulação. As características desse fluxo estão determinadas por fatores como as estratégias, as informações prévias, as relações interpessoais, a influência do contexto sociocultural, a intencionalidade, as regras e mecanismos. (GARCIA, 1988).

Dentre os objetivos da educação formal, salientamos, então que dois são fundamentais: um é oportunizar ao educando o desenvolvimento de uma postura crítica que lhe permita atuar na sociedade; o outro é fornecer condições para o desenvolvimento cognitivo dos educandos. Neste contexto, parece-nos imprescindível o desenvolvimento de pesquisas que revelem aos profissionais da área de Ensino de Ciências caminhos para o desenvolvimento de atividades que abordem questões referentes aos assuntos que despertem o interesse dos alunos, intervindo em sua iniciativa pessoal e provocando o esclarecimento de idéias, a discussão e o debate.

Com isso, trazendo informações de fora da escola, seja por contato com o meio, por conversas com outras pessoas ou por idéias veiculadas em meios de comunicação, os alunos possivelmente demonstrarão interesse acentuado e, diante desse elemento motivador, outras questões sobre cultura, saúde, educação, emergem, o que significa discutir não apenas conteúdo, mas desenvolvimento humanístico. Assim, poderão desenvolver uma visão integrada da realidade, com responsabilidade no uso dos recursos naturais, respeitando o ambiente e a qualidade de vida. Propomos a abordagem de conteúdos significativos dentro de uma perspectiva transformadora, no intuito de propiciar aos alunos a oportunidade de ampliarem a leitura da realidade e a conscientização, podendo promover transformações sociais.

Discussões a respeito da natureza do conhecimento científico e do ensino de Ciências e de Biologia estão acontecendo há mais de 20 anos, ainda hoje, via de regra, a 
visão da ciência apresentada pelos (as) professores (as) nas escolas, é aquela cujos pressupostos nortearam a ciência do século XVII, ou seja, uma imagem mecânica do mundo, uma visão fragmentada. O mundo é conhecido pelo estudo mais especializado das partes que o compõe, como se cada parte funcionasse isoladamente. Esta visão fragmentada ainda continua influenciando os currículos escolares de todas as disciplinas da educação científica. (Brito, Sousa e Freitas, 2003). Fato este que dificulta a compreensão do aluno e que queremos combater, buscando na contextualização ferramentas que possam nos indicar caminhos onde as diferentes disciplinas possam discutir elaborando conceitos sólidos, visando ao aluno uma compreensão do processo científico, bem como fatores diversos como interesses sociais, econômicos, éticos, entre outros, que pode influenciar diretamente na produção da ciência que é dinâmica e, portanto está em constante construção. O homem faz parte desse processo moldando-o no decorrer da história.

A interação entre ciência e sociedade é complexa e muitas dificuldades são encontradas. Podemos salientar a dificuldade de o público perceber as implicações do conhecimento científico em seu cotidiano. Isso também pode ser observado na prática educativa centrada em leis, teorias e concepções que não respondem às necessidades do estudante (Martin-Diaz, 2003).

Podemos observar o conhecimento como uma relação dialética, mediada semioticamente, entre o sujeito e o objeto. Nesse processo o papel do mediador e da linguagem é essencial. Pino (2001) aput Vygotsky mostra a relação entre linguagem e pensamento

"O mundo das singularidades, não pode ser objeto do conhecimento dito científico, fundado na abstração generalizante. Por outro lado, sendo a imagem mental a reconstituição da singularidade, ela também não é um bom guia nesse tipo de conhecimento. Só a representação dessa imagem pela sua forma simbólica permite sair do mundo das singularidades para entrar no das generalizações ou da conceitualização".

Outro fator que devemos salientar é que nossas escolas sempre refletem as mudanças política, econômicas, sociais e culturais procedentes da sociedade. As modalidades didáticas utilizadas para o ensino de Ciências dependem da concepção de ciência adotada, suas temáticas também se relacionam ao enfoque do ensino científico. (Krasilchik, 2000).

Krasilchik (2000) demonstra em seu artigo que a própria pesquisa em Ensino de Ciências se modela de acordo com as concepções e enfoques relacionados à área. Hoje 
se busca o trabalho interdisciplinar integrando as disciplinas relacionadas à Ciência, tais como, a química, a física, a matemática e a biologia. A discussão de problemas, o trabalho em laboratório, o aperfeiçoamento de professores são apenas algumas das muitas atividades de investigação nos meios acadêmicos.

Nesse enfoque, esse estudo tem por objetivos verificar o aprendizado de conceitos científicos sobre a questão de produção de energia e ao mesmo tempo identificar se os alunos estabeleceram relações com determinantes sócio-econômicos, tecnológicos e fatores ambientais, buscando integrar disciplinas afins que possam contribuir para uma melhor compreensão desses conceitos.

As atividades desenvolvidas na escola devem seguir princípios básicos tais como, ter sentido em si mesma para o aluno, mobilizar suficiente energia interna (motivação), ter uma notável capacidade de mobilizar informações potencialmente significativas para os alunos e admitir diversas possibilidades de desenvolvimento. (CAÑAL, 1988).

Por fim, salientamos a importância desse trabalho multi e interdisciplinar que busca subsídios nas relações cotidianas da sociedade, na interação biológica de seres vivos e o ambiente no cultivo da cana-de-açúcar. As reuniões e planejamento dos professores foram o primeiro passo de discussão, contextualização e formulação de estratégias didáticas que pudessem favorecer a execução de um projeto voltado às necessidades da Unidade Escolar. Nosso segundo passo relacionou-se aos alunos e a aplicabilidade deste projeto. Um terceiro passo constou da análise dos dados e conclusões sobre o desenvolvimento das atividades com os alunos. Buscamos como possibilidade, a produção de uma metodologia ampla, que possa ser utilizada frente a outras realidades, ou seja, estratégias que permeiem a complexidade do contexto escolar inserido em um contexto social.

\section{METODOLOGIA}

O projeto foi realizado em uma escola localizada em uma cidade onde a principal fonte de renda provém da produção de cana-de-açúcar. Sendo a escola um espaço onde professores e alunos podem realizar, manipular e intervir diretamente em experimentos que instiguem a curiosidade e a percepção na construção científica buscaremos recursos didáticos que integrem o grupo e possibilitem a discussão de conceitos científicos. 
A escolha do tema Cana-de-açúcar possibilitou uma ampla discussão entre os professores de áreas correlatas durante os HTPC. Levantamentos de várias hipóteses de condução do projeto foram relatados, porém a escolhida consta da aquisição de maior número possível de dados e de uma pergunta norteadora para que com o próprio interesse dos alunos, seus questionamentos e seus conhecimentos prévios pudéssemos conduzir o projeto.

Os registros foram realizados através do planejamento, das anotações de professores e alunos, da gravação das discussões e posterior transcrição dos dados, da confecção de cartazes e maquetes e de textos informativos.

A série escolhida foi a $3^{\mathrm{a}}$ série do Ensino Médio (A e B) do período noturno. Os alunos foram questionados quanto ao interesse de participar de um projeto de pesquisa e a resposta das salas sendo positiva o projeto deve continuidade. Iniciamos as atividades vinculando o projeto aos estudos já realizados pelos estudantes dessa série. O foco principal foi o ambiente (cultivo de uma monocultura), uma vez que, essas salas estavam realizando estudos nessa área. Os professores reunidos fizeram um levantamento de conceitos científicos em cada área disciplinar que poderiam subsidiar o projeto temático. O quadro a seguir descreve o levantamento realizado pelos professores.

\begin{tabular}{|c|l|}
\hline Disciplinas & \multicolumn{1}{|c|}{ Conceitos científicos e matemáticos } \\
\hline Biologia & $\begin{array}{l}\text { Ecologia, produtividade primária do ecossistema, ciclos } \\
\text { biogeoquímicos, fluxo de matéria e energia, biodiversidade e } \\
\text { degradação ambiental. }\end{array}$ \\
\hline Física & $\begin{array}{l}\text { Ondulatória, ondas eletromagnéticas, o espectro eletromagnético, } \\
\text { tipos de radiação, radiação e efeito estufa, a emissão de poluentes } \\
\text { por motores veiculares, biocombustíveis, combustíveis } \\
\text { alternativos, protocolo de Kyoto. }\end{array}$ \\
\hline Matemática & $\begin{array}{l}\text { Tratamento dos dados e informações advindas das outras } \\
\text { disciplinas, tabelas e gráficos. }\end{array}$ \\
\hline Química & $\begin{array}{l}\text { O estudo das Ligações Químicas; O estudo das Misturas e suas } \\
\text { Separações; O estudo das Reações Químicas; O estudo da Química } \\
\text { Orgânica. }\end{array}$ \\
\hline
\end{tabular}

Quadro 1: Descrição dos conteúdos das disciplinas relacionadas a ciências da natureza (segundo PCN Ensino Médio)

Nas aulas de biologia discussões sobre a produtividade de um ecossistema foi o ponto de partida para o início do projeto. Após esses conceitos serem formulados os alunos foram questionados sobre o ciclo da matéria e energia no ambiente. Os ciclos biogeoquímicos do Carbono e do Oxigênio enfatizaram as questões ambientais 
relacionadas ao efeito estufa e aos conceitos de respiração e fotossíntese, bem como, seus subprodutos. Quando falamos em energia (fundamentalmente a formação da molécula de glicose) intervenções do professor de química realizaram-se para explicar como as moléculas armazenam energia através de ligações químicas.

$\mathrm{Na}$ primeira aula (discussões sobre produtividade primária) perguntou-se aos alunos sobre o que eles compreendiam sobre produtividade primária no ecossistema. As respostas incluíam as seguintes categorias:

$1^{\mathrm{a}}$ - relacionada ao crescimento e reprodução das plantas;

$2^{\mathrm{a}}$ - relacionando com o solo;

$3^{\mathrm{a}}$ - relacionando a ecologia.

A maioria das respostas relacionou a produtividade primária com o desenvolvimento da planta (crescimento), outros falaram sobre a questão do solo (nutrientes), e poucos falaram sobre a produção de glicose e o armazenamento da mesma ou sobre balanço energético (relação entre consumo e gasto).

Aproveitando os comentários sobre crescimento das plantas e os nutrientes no solo os alunos foram questionados quanto ao desenvolvimento dos vegetais quais processos estão relacionados. As respostas obtidas foram:

$1^{\mathrm{a}}$ - através de mitose;

$2^{\text {a }}$ - através do alimento;

$3^{\mathrm{a}}$ - através da fotossíntese.

Outras questões foram formuladas sobre como esse crescimento seria possível através das hipóteses levantadas. As primeiras consultas bibliográficas foram realizadas nesse momento. Em grupos, e com livros didáticos de biologia, os alunos buscaram informações sobre esses processos e depois cada grupo apresentou seus resultados e novas discussões foram formuladas. Nesse momento o professor de química participou das discussões demonstrando como as moléculas (principalmente as de glicose) eram formadas.

O professor de física discutiu alguns conceitos relacionados à ondulatória (luz e calor) fundamentais para a compreensão do efeito estufa. As aulas de matemática forneceram subsídios para o desenvolvimento de gráficos e tabelas comparativas sobre as condições climáticas relacionadas à produção de dióxido de carbono.

O professor de Química realizou um estudo sobre as Ligações Químicas, enfatizando os produtos açúcar (sacarose) e o álcool; ao realizar um estudo sobre as Reações Químicas (fermentação) e Separação das Misturas (destilação fracionada), 
onde ambas fazem parte dos processos de obtenção do açúcar e do álcool, o estudo da Química Orgânica será voltado para as funções HC e Álcool.

Discutimos, ainda, questões voltadas ao trabalhador rural, sua qualidade de vida e o que aconteceria com esse produtor com a automação do cultivo da cana-de-açúcar. Preocupação presente na fala dos alunos uma vez que a economia da cidade e, portanto, de suas casas está intimamente ligada ao trabalhador rural.

Como na região há tanto uma usina de açúcar e álcool como uma usina hidroelétrica a discussão sobre outras fontes de energia também foi objeto de estudo desse projeto. Uma visita a essas duas usinas, a utilização e produção de diferentes formas de energia e o impacto ambiental, social, econômico e político que essa temática pode levantar configuraram elementos norteadores para a continuação dessas discussões. Para a finalização do projeto ocorreu uma exposição, no pátio da própria escola, dos resultados obtidos através de cartazes, maquetes, fotos, relatos transcritos e trabalhos de pesquisa realizados pelos alunos no decorrer das atividades.

Ao final das atividades os alunos fizeram dissertações sobre o tema e pudemos observar as categorias demonstradas no quadro a seguir e percebemos a integração do aluno com a problemática em questão. Estatisticamente temos os seguintes itens e suas proporções de acordo com o número de redações (cada redação pode conter mais de um item): 

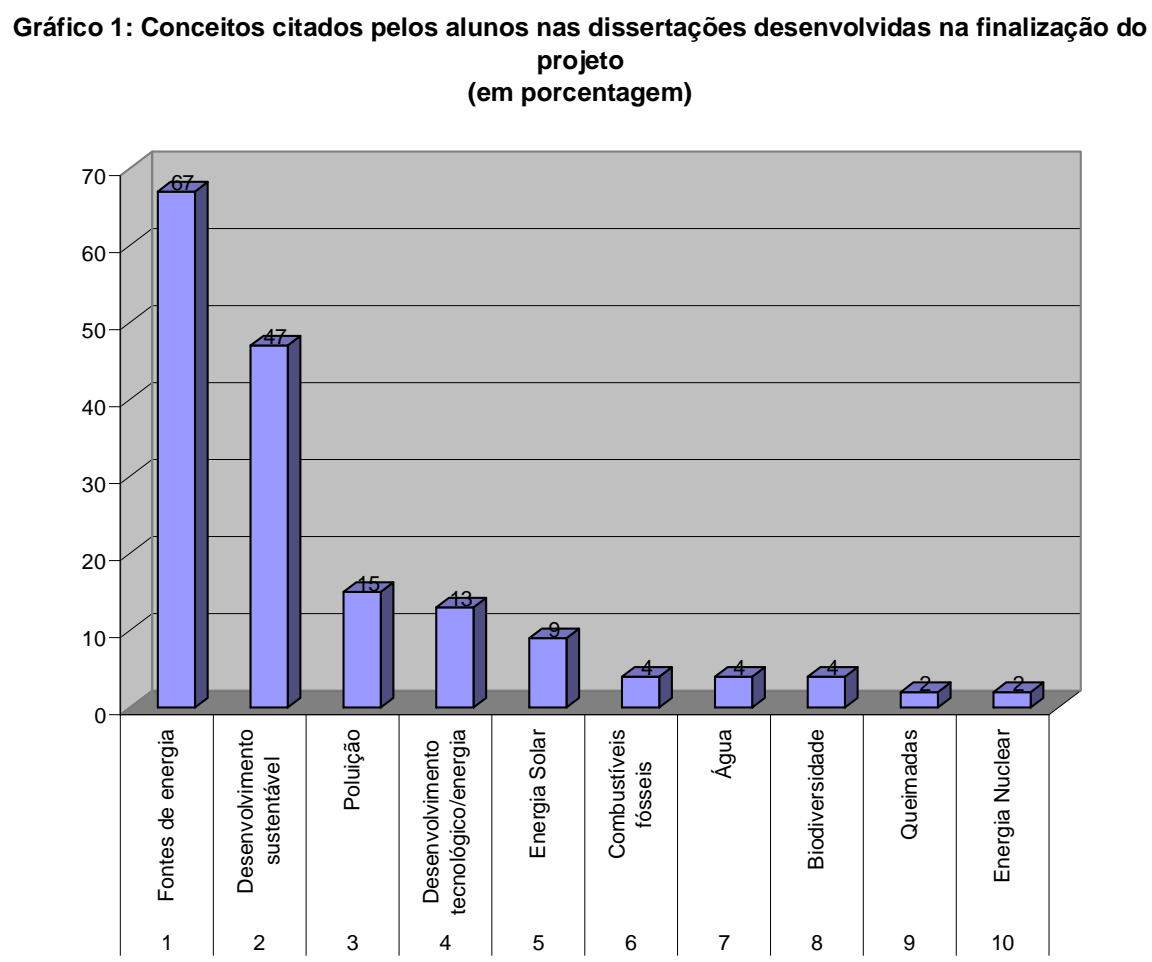

Esses resultados mostram a preocupação dos alunos com o uso das fontes de energia e o desenvolvimento sustentável (foco desse trabalho), porém podemos observar também que outras questões foram levantadas considerando as discussões em sala de aula como a problemática da água e da poluição e a biodiversidade no planeta. Posteriormente alguns trechos das dissertações e discussões serão transcritos para que possamos analisá-los.

No interior desse planejamento didático foi realizada uma pesquisa buscando identificar o interesse dos alunos em participar de atividades interdisciplinares.

\section{DISCUSSÕES}

Durante a realização do projeto dois fatos importantes, destacados durante as discussões com os professores da Unidade Escolar em questão, foram: a) o interesse dos alunos - mesmos os que apresentavam uma dificuldade de aprendizagem ou de atenção desenvolveram muito bem todas as atividades vinculadas ao projeto - b) a facilidade de articulação das áreas correlatas trabalhando de maneira interdisciplinar com o projeto. A princípio apenas biologia, química, física e matemática se reuniam para as discussões durante o HTPC (Horário de Trabalho Pedagógico Coletivo) depois os professores de 
geografia, história, língua portuguesa e até educação artística se envolveram no projeto, em questões como correção dos textos e cartazes, auxiliando na confecção de cartazes e maquetes, indicando as dimensões históricas e geográficas dos impactos ambientais. Enfim todas as disciplinas se envolveram no tema Energia e Impacto Ambiental e os alunos puderam observar amplamente a problemática discutida. No projeto pedagógico para 2007 há uma possibilidade de implantação dessa temática como eixo norteador dos planos de ensino de toda a Unidade Escolar (sugestão dos próprios professores).

Depois de compreender como os fenômenos de armazenamento e utilização dos produtos orgânicos ocorreram questões sobre como esses processos sofrem interferência humana foram levantadas. Questões sobre os impactos ambientais surgiram, a partir do interesse dos alunos, e, portanto, foram discutidas. Concomitantemente as questões sobre a Energia e sua utilização pela humanidade também começaram a ser discutidas e os temas álcool e energia hidroelétrica logo surgiram pela proximidade de usinas de açúcar e álcool e hidroelétrica na região.

Durante as discussões sobre os impactos ambientais e a energia os professores de física e matemática participaram das discussões explicitando os mecanismos físicos sobre ondulatória, calor, discussões sobre o protocolo de Kyoto, análises matemáticas dos gráficos e tabelas e elaboração de cartazes com as análises realizadas pelos alunos.

Enquanto discutíamos as questões da produção de Energia a questão dos trabalhadores rurais também foi suscitada. Muitos dos alunos têm seus pais ou parentes ou eles próprios que trabalham diretamente ou indiretamente com o cultivo da cana-deaçúcar ou na Usina Hidroelétrica no município. A professora de história promoveu discussões em suas aulas sobre as organizações sociais e o trabalho, as mudanças na sociedade e na mão de obra. A professora de geografia discutiu os espaços utilizados e as mudanças geográficas. Entrevistas com avós ou parentes mais velhos sobre como era a região antes da construção das usinas e analise desses dados foram realizadas por esses professores.

Os professores de língua portuguesa auxiliaram durante todo o processo com textos relacionados à área e com a correção dos textos dos alunos. Ao final do projeto os alunos desenvolveram uma dissertação onde relataram os pontos que julgaram mais importantes de toda a discussão. No final do ano letivo os trabalhos foram expostos na escola e tanto os outros alunos como a comunidade (que visita a escola aos finais de semana através do programa Escola da Família) puderam observar os trabalhos realizados pelos alunos. 


\section{III. a) Dados e discussões referentes ao interesse dos alunos em participar do} projeto.

Os professores que integraram o projeto pedagógico, que se reuniram para montar, desenvolver e finalizar o projeto relataram o grande interesse demonstrado pelos alunos. Durante as discussões, dentro das mais diversas áreas, sempre surgiam comentários que relacionavam as diferentes disciplinas escolares. Um dos professores relatou

\section{“... foi muito interessante ouvir alunos relacionando um mesmo assunto em diferentes disciplinas...”}

Os professores de química, física e biologia que formam áreas correlatas trabalharam os mesmos conceitos científicos enfocando aspectos específicos de cada área, podemos observar esse trabalho quando falamos, no início do projeto, de produção de matéria orgânica pelas plantas (fotossíntese). Os três professores estudaram com seus alunos o mesmo projeto, porém o de biologia trabalhou o processo para formação da molécula de glicose, o professor de física trabalhou as questões da óptica e da ondulatória e o de química as questões relacionadas às moléculas orgânicas e principalmente a conservação de energia nas ligações químicas. Portanto, em um mesmo fenômeno (fotossíntese) três diferentes áreas desenvolveram seus conceitos específicos. Os alunos também aprovaram essa organização metodológica, um deles inclusive relatou:

“... agora sim entendo porque tenho que estudar tudo isso, parece simples, mas uma coisa faz parte da outra e uma coisa explica a outra..."

Relato de um aluno ao professor de Biologia

Quando o projeto estava em andamento e outros professores de outras áreas começaram o observar o interesse dos alunos pediram para participar das discussões nos horários do HTPC. Um deles ressaltou:

“... os alunos comentaram sobre o que vocês estão fazendo e percebi que posso trabalhar junto com vocês. A geografia tem muito a dizer sobre as questões energéticas também..."

Relato do professor de Geografia 
O diretor e os coordenadores da Unidade Escolar também demonstraram sua vontade de participação no projeto e convidaram os professores responsáveis para desenvolver um planejamento anual, envolvendo toda a escola com temas geradores, sendo um deles o tema Energia que foi foco desse trabalho.

Os alunos participaram ativamente do processo. Alguns trabalham nas usinas da região e trouxeram muitas informações sobre a organização interna do trabalho nessas unidades. Os alunos que trabalham indiretamente com a cana-de-açúcar também relataram os impactos que a monocultura traz a região. Desde impactos como aumento das vendas no comércio local na época de safra, até o aumento de pacientes que procuram o serviço público de saúde.

O projeto iniciou-se com uma questão norteadora que foi a produção de energia pelas plantas (que foi subsidiado pelas informações de produtividade primária no ecossistema e posteriormente o processo de fotossíntese e respiração). A continuidade da atividade na Unidade Escolar só foi possível através das discussões dos alunos que conduziram o projeto posteriormente. As discussões realizadas em sala de aula (com os alunos) eram revistas semanalmente pelos professores nos horários de trabalho coletivo. Nesse momento todas as questões eram revistas e novas decisões e percursos eram traçados. Algumas mudanças nos rumos iniciais eram realizadas de acordo com as necessidades e as reuniões nunca deixaram de ser realizadas entre os professores. Percebemos, tanto entre os professores como entre os alunos, um entusiasmo em relação ao projeto e as atividades interdisciplinares. A articulação dos conceitos estão descritos no item posterior.

\section{III. b) Dados e discussões que apresentam as relações estabelecidas entre as áreas disciplinares e a articulação entre conceitos e impactos ambientais e determinantes sócio-econômicos.}

Com esse projeto pretendíamos avaliar a formação de conceitos científicos e as relações estabelecidas pelos alunos entre esses conceitos e os impactos ambientais e os determinantes sócio-econômicos. Portanto na finalização do projeto pedimos que todos os alunos fizessem uma dissertação com o tema do projeto que era energia e desenvolvimento sustentável. Nas dissertações pudemos observar essas relações como transcrevemos a seguir. 
"mas com o passar dos anos o homem passou a transformar esse ambiente para construir cidades, industrias, rodovias... e não se preocupou com as conseqüências. Mas o homem é totalmente dependente do meio ambiente e de tudo o que ele oferece, sabe que qualquer coisa que faça para o meio ambiente estará fazendo a si mesmo... ...Atitudes como economizar energia, cooperar com a reciclagem contribuem para a preservação do meio ambiente. Criar certos hábitos desde já demonstra o quanto nos importamos com a vida na Terra."

(Aluna J. F. M. - $3^{a}$ série EM)

Nesse primeiro trecho a aluna relaciona o impacto ambiental com a necessidade energética demonstrando que o homem necessita dos recursos naturais mas deve usá-los de forma adequada, criando novos hábitos de consumo.

"Tem que haver uma integração entre preocupação sociais, ecológicas e econômicas para conseguir novas soluções para o controle e a minimização dos danos ao ambiente. Devemos preservar os bens da natureza e garantir um "verde" de esperança para as gerações futuras."

(Aluno V. C. T. $3^{a}$ série EM)

“...com a idéia de desenvolvimento sustentável, o homem procura interagir com a natureza com alguns aspectos prioritários: satisfação básica da população, preservar o ambiente, participação de empresas e da população, preservação dos recursos naturais e utilizando-os com parcimônia, reciclando e erradicando a miséria... ...na questão energética o homem está preocupado em substituir recursos não-renováveis e que poluem por recursos renováveis e menos poluentes."

(Aluno B. H. S. $3^{a}$ série EM)

Nesses dois trechos os alunos demonstram claramente suas preocupações com as questões sociais, ecológicas e econômicas vinculadas aos já existentes danos ambientais. A integração desses fatores com o ambiente mostra a compreensão da questão do desenvolvimento sustentável e a articulação dos conceitos que pretendíamos.

“...a energia é também um dos fatores que pode minimizar os impactos ambientais como energia alternativa que não é baseada em combustíveis fósseis, as que não são renováveis e provoca em maior quantidade a poluição do ar em conseqüência causando o efeito estufa que é o efeito global, que tem aumentado a temperatura... 
...novas técnicas de energia "limpa" tem que ser utilizadas de forma sustentada para diminuir o impacto ambiental."

(Aluna A. R. C. $3^{a}$ série EM)

Agora podemos observar a preocupação com fontes renováveis e o impacto ambiental provocado pelo uso inadequado de energia mostrando uma integração entre áreas correlatas.

“...não adianta falar que precisamos ter consciência de tudo o que está acontecendo, pois todos nós sabemos os problemas que o homem está causando ao meio ambiente, tais como poluição..., o efeito estufa,...até o lixo doméstico é um poluente para o país... por isso eu digo que só tomar consciência não basta, precisamos acreditar que temos condições de tentar mudar para melhor. Tudo depende de nós se quisermos mudar, e lutamos para que isso aconteça, com certeza acontecerá..."

(Aluna R.C.G. $-3^{a}$ série EM)

Esse trecho demonstra que a aluna relata as questões relacionadas aos impactos ambientais provocado pela ação humana e a tomada de decisão pelos indivíduos e pela sociedade em geral.

\section{CONCLUSÕES}

Devemos ressaltar que apesar das discussões terem como foco principal a realidade da Unidade Escolar não foram apenas esses os assuntos discutidos. As intervenções dos professores instigando os alunos a buscar novas hipóteses e respostas para a problemática ressaltada em sala de aula promoveram a discussão de inúmeros conceitos científicos gerando uma alfabetização científica dos educandos e permitindo uma leitura mais ampla da realidade social, tanto local como mundial.

O trabalho interdisciplinar foi possível graças às reuniões periódicas dos professores envolvidos. Essas reuniões aconteceram anteriormente ao início do trabalho com os alunos permitindo aos professores conhecimento do tema e a articulação prévia das áreas correlatas. $\mathrm{O}$ interesse dos alunos foi uma caracterização notória do projeto que inclui novos professores em nossas reuniões e no desenvolvimento do projeto.

A ciência como conhecimento está em constante crescimento e, portanto traria consigo uma subdivisão dos campos de investigação e um aumento do universo de pesquisadores. Mas, o crescimento da ciência não se pauta apenas nesses dois fatores, 
ele resulta numa constante emergência de novas disciplinas que não são mais do que a estabilização institucional e epistemológica de rotinas de cruzamento de disciplinas caracterizando a interdisciplinaridade. (Pombo, 2006)

Como já previsto pelos PCN e sendo a escolaridade básica obrigatória findada no $3^{\circ}$ ano do Ensino Médio os alunos devem dominar a linguagem cientifica, bem como, o conhecimento de seu cotidiano e das influências das decisões municipais, estaduais, federais e até mundiais em seu dia-a-dia. Com discussões como as que foram desenvolvidas nesse projeto essas condições são satisfeitas e o aluno pode compreender os mecanismos de regulação de uma sociedade, principalmente daquela que está envolvido.

Podemos concluir e salientar que com reuniões periódicas e temas unificadores projetos interdisciplinares são formadores de conceitos científicos articulados com fatores socioeconômicos, políticos, ambientais, entre outros.

\section{REFERÊNCIAS BIBLIOGRÁFICAS}

BRASIL (MEC) Parâmetros Curriculares Nacionais: Ensino Médio. Brasília, Secretaria de Ensino Médio e Tecnológico, 1999.

BRITO, L. D.; SOUZA, M. L.; FREITAS, D., A busca de um dialogo sobre a natureza do conhecimento cientifico e a relação CTSA na formação de professores (as) de ciências e biologia. IV Encontro Nacional de Pesquisa em Educação em Ciências, Bauru, São Paulo, 2003.

CAÑAL, P., Un Marco curricular en el modelo sistémico investigativo, em Garcia, Cañal e Porland: Constructivismo y enseñanza de las ciencias, Díada, Sevilla, 1988

GARCIA; J. E., Fundamentos para la construccion de un modelo sistémico del aula, em Garcia, Cañal e Porland: Constructivismo y enseñanza de las ciencias, Díada, Sevilla, 1988.

GIMENO SACRISTÁN, J., PÉREZ GÓMEZ, A. Compreender e transformar o ensino. Porto Alegre: Artmed, 1998.

KRASILCHIK, M., Reforma e realidade: o caso do ensino de ciências. São Paulo em perspectiva, 14 (1), 2000. p. 85-93.

MARTIN-DIAZ, M. J., El papel de las ciencias de la naturaleza en la educacion a debate. Revista Iberoamericana de Educación, Madri, n³3/2, 2004.

MORIN, E., Ciência com consciência. Tradução Maria D. Alexandre e Maria Alice Sampaio Doria - Rio de Janeiro: Bertrand Brasil, 1996. 
PINO, A., O biológico e o cultural nos processos cognitivos. Linguagem, cultura e cognição - reflexões para o ensino e a sala de aula. Organizado por Eduardo Fleury Mortimer e Ana Luiza Bustamante Smolka. Belo Horizonte, Autêntica, 2001.

POMBO, O., Práticas interdisciplinares, Sociologias, Porto Alegree, ano 8, $\mathrm{n}^{\circ} 15$, jan/jun 2006. 